\title{
Violencia urbana: un asunto de ciudad ${ }^{*}$
}

\author{
FERNANDO CARRIÓN M.**
}

**Concejal del Distrito Metropolitano de Quito, Coordinador del Programa de Estudios de la Ciudad de Flacso-Ecuador y Editorialista Diario Hoy.

\begin{abstract}
The city is the space where multiple social activities occur and where new and diverse forms of violence appear. This has been a major research topic in the last two decades, which has been analyzed in addition to other factors with particular effects on Latin American cities. However, this has not been considered a phenomenon that is part of new forms of urban life, so we need innovative urban policies that are based in reality. We analyze violence by focusing on its causes and different forms, the city as a scenario for violence, the effects of violence on the city, and public space as a scenario for crime.
\end{abstract}

KEYWORDS: violence, city, public space, urban policies.

RESUMEN La ciudad es el espacio donde se desenvuelven múltiples acciones sociales y bajo la cual también se desarrollan variadas y nuevas formas de violencia. Este ha sido un tema importante en las dos últimas décadas, que se ha sumado a factores que afectan especialmente a Latinoamérica. Pese a eso no ha sido considerado como temática incorporada a las nuevas formas de vida urbana, por lo que requiere de políticas urbanas innovadoras que se relacionen directamente con la realidad. Se analiza la violencia enfocada en la causalidad tipos de violencia, la urbe como escenario de la violencia, los efectos producidos por la violencia en la ciudad y el espacio público como escenario del delito.

PALABRAS CLAVES: violencia, ciudad, espacio público, políticas urbanas.

\footnotetext{
* Agradezco los comentarios de Alfredo Rodríguez (SUR) y Carlos de Mattos (EURE) a la versión inicial del documento.

Recibido el 23 de septiembre de 2008, aprobado el 3 de noviembre de 2008.

E-mail: fcarrion@flacso.org.ec.
} 


\section{"El espacio público es la ciudad" \\ Oriol Bohigas}

\section{Introducción}

Durante los últimos 20 años, la violencia se ha convertido en uno de los temas más importantes de las ciudades latinoamericanas, debido al cambio en sus formas (un grado mayor de violencia), a los impactos (sociales y económicos), al incremento de su magnitud (se duplicó) y al aparecimiento de nuevos tipos (secuestro express, violencia en los estadios, entre otros).

La violencia se ha extendido por todos los países y ciudades de la región con peculiaridades y ritmos propios, provocando varios cambios: en la lógica del urbanismo (blindaje de la ciudad, nuevas formas de segregación residencial); en los comportamientos de la población (angustia y desamparo); en la interacción social (reducción de ciudadanía, nuevas formas de socialización); y en la militarización de las ciudades (mano dura, ejército en las calles), todo esto amén de la reducción de la calidad de vida de la población (homicidios, pérdidas materiales).

Pero también el modelo actualmente vigente de ciudad produce clases de violencias nunca antes vistas (sicariato, coches bomba), así como otras "no delictuales", provenientes de la fragmentación, la exclusión, la densidad poblacional y la disputa por el espacio público y los servicios.

En otras palabras, a los problemas de transporte, medio ambiente, pobreza, equipamientos, vivienda y gobernabilidad de nuestras ciudades se ha incorporado la violencia; lo cual requiere de nuevas políticas urbanas, y también políticas explícitas de seguridad ciudadana, porque no sólo se ha convertido en un problema urbano adicional sino ahora tiene autonomía propia y afecta a otros componentes de la sociedad y la ciudad.

A pesar de la trascendencia de la violencia en las ciudades latinoamericanas, aún no existe un correlato respecto de su conocimiento, porque no se le ha concedido tal importancia, ni ha sido incorporada en la discusión de los problemas del desarrollo y de las formas de vida urbana. En esa perspectiva, el tema de la relación ciudad - violencia es - probablemente- uno de los menos estudiados y conocidos, porque, en primer lugar, hay un problema metodológico que nace de una definición de violencia entendida a partir de ciertos atributos y no de relaciones sociales, lo que impide conocer con profundidad la violencia y establecer los puentes correspondientes con la ciudad ${ }^{1}$. A pesar de ese desconocimiento, incluso desdeñado, se ejecutan políticas y acciones explícitas.

Por eso, cada uno de los polos de la relación ha sido investigado independientemente, sin que se haya logrado construir la anhelada vinculación. Y, cuando se ha intentado establecer

\footnotetext{
1 La OMS/OPS define la violencia como "El uso intencional de la fuerza o el poder físico, de hecho o como amenaza, contra uno mismo, otra persona o un grupo o comunidad, que cause o tenga muchas probabilidades de causar lesiones, muerte, daños sicológicos, trastornos del desarrollo o privaciones” (2002, p. 5). Es una definición instrumental que no cuenta con la posibilidad de identificar actores, circunstancias y menos aun condiciones históricas.
} 
algún vínculo entre ellos, se lo ha hecho bajo un determinismo unívoco de lo urbano hacia la violencia. De allí que las propuestas de política de seguridad en las ciudades tengan mucho más que ver con supuestos ideales que con sus realidades.

Sin duda, esta es una asignatura pendiente, algo que está por hacerse. Definir su punto de partida metodológico es vital; por eso, más que exponer resultados de estudios realizados, con este trabajo se presentan algunas preguntas que pueden ser relevantes para entenderla. Se busca llamar la atención respecto de la necesidad de conocer esta relación y, para ello, recurrimos a algunas interrogantes que pueden establecer ciertos elementos clarificantes.

- Una primera pregunta tiene que ver con el criterio metodológico establecido para conocer la violencia: la causalidad. En esa perspectiva, y dada la lógica anti-urbana prevaleciente, la pregunta se dirige a saber si efectivamente existe una causalidad urbana en la violencia.

- La segunda interrogante está relacionada con el hecho de que, si la ciudad es solamente un contenedor de los hechos delictivos (lugar físico de las acciones violentas), ello supondría que existe una autonomía de ésta frente a la violencia. Por eso, preguntarse si la ciudad es un escenario -aunque no externo- del delito, es absolutamente pertinente; en tanto locus de las prácticas sociales que tienen expresión espacial.

- El tercer cuestionamiento está dirigido a comprender, desde la perspectiva conceptual, un elemento central: si la violencia es plural, es totalmente factible encontrar una clase de violencia que tenga un origen específicamente urbano; sobre todo, si entendemos a la ciudad como el lugar donde se concentra la mayor densidad de la heterogeneidad y, por lo tanto, donde la ritualidad de la vida cotidiana puede producir roces, conflictos y contradicciones que desemboquen -si no se los procesa adecuadamente- en hechos de violencia típicamente citadinos.

De estas preguntas se desprenden unas adicionales: ¿cómo deberíamos tratar estas violencias? ¿Con políticas urbanas, con políticas de seguridad ciudadana o con una combinación de ellas? Las llamadas causalidades clásicas de la violencia: desigualdad, empleo, educación y unidad familiar, ¿son urbanas?

Para intentar responder estas preguntas, seguiremos una lógica expositiva, compuesta por los siguientes acápites: el primero, en que se cuestiona la causalidad en la relación ciudad/tipos de violencia; el segundo, que analiza si la violencia es o no efecto de la ciudad, si la urbe es contenedor (escenario) y/o expresión de una específica (violencia urbana); el tercero, que está dedicado a la presentación, por un lado, de algunas manifestaciones de la ciudad en la violencia y, por otro, de los efectos producidos por la violencia en la ciudad; el cuarto busca aproximarse al espacio público como escenario (¿productor?) del delito; para, finalmente, extraer algunas conclusiones que pueden ser relevantes.

\section{Ciudad y violencia: dos equívocos de su incomprensión}

Las "violencias" y las ciudades cambian constantemente, mutando la relación entre ellas porque son históricas; sin embargo, el desconocimiento de la transformación de la relación de las violencias con la ciudad -y viceversa- ha llevado a varios equívocos, entre los que se 
pueden señalar -al menos- dos que son centrales para el presente trabajo, el uno (la política) consecuencia del otro (las concepciones):

- Concepción. Existe una visión dominante, que es sostenida por la irresistible tentación metodológica de encontrar causalidad de la violencia en la ciudad ${ }^{2}$, mediante un anti-urbanismo insostenible, que lleva a creer que la violencia urbana es sinónimo de violencia y que la ciudad - per se- es el origen la violencia, con lo cual la ciudad termina criminalizada. Esto es, que la violencia es urbana y lo urbano la determina.

Justo es señalar que esta causalidad también se sustenta en una visión negativa de la ciudad. Ya que, durante mucho tiempo, se la consideró como un problema, básicamente por las cargas pesimistas que tenían las concepciones dominantes; primero, como fuente de caos y anomia (violencia) y, segundo, como un producto artificial que desafía la naturaleza (riesgo). Estos factores sólo eran controlables si se impedía el crecimiento de la ciudad, mediante la contención de la migración del campo. Hoy, esta opinión intenta ser superada, porque hay corrientes que empiezan a ver a la ciudad como una solución. Mientras la mujer se visibiliza y se hace pública ${ }^{3}$, la pobreza se reduce ${ }^{4}$, el empleo es de mayor calidad y el desempleo menor (OIT, 2003), los servicios son superiores y las tasas de violencia son distintas a las del campo, entre otras. En otras palabras, la ciudad no es un abstracto sino un modelo concreto de desarrollo urbano, afín a un tipo particular de violencia (delictual y no delictual); lo que quiere decir que la violencia urbana $a^{5}$ puede ser reversible, bajo un urbanismo distinto al vigente en la región.

- Políticas. De la ausencia de estudios y de la visión determinista de lo espacial en la violencia, propia del pragmatismo ideológico reinante, se construye un conjunto de propuestas que no tienen anclaje en la realidad; entre las más relevantes constan las siguientes:

$\rightarrow \quad$ La llamada prevención situacional, que no es otra cosa que la necesidad de reducir las oportunidades a la violencia en las víctimas (actividades rutinarias) y a los estímulos a los victimarios (elección racional), a partir de los espacios o sitios proclives a la realización del crimen (diseño urbano) (Crawford, 1998) ${ }^{6}$.

\footnotetext{
2 Por eso, en la definición de violencia urbana se tienen tres acepciones: una, que le endilga a lo urbano la cualidad causal; otra, que le asigna la condición de un tipo particular de violencia; y la tercera, que la presenta como si fuera símil de violencia.

3 "Según Anderson, esta presencia creciente de mujeres en las ciudades revela factores y procesos sociales y económicos complejos, entre los cuales se puede incluir el que las ciudades proveen condiciones de "viabilidad" para mujeres solteras, mujeres que desean independizarse y madres solas" (Arboleda, 1999, s/n).

4 "En la mayoría de los países la concentración urbana no ha sido un factor negativo, pues ha permitido el acceso a bienes y servicios en una medida bastante mayor que la prevaleciente en tiempos de predominio rural” (Jordán y Simiodi, 2002, p. 15).

5 "No es casualidad que la policía haya inventado, durante aquellos años, la categoría burocrática de 'violencias urbanas', basada en una escala pseudocientífica de grados de agresión (de la que el 'agrupamiento de jóvenes en la escalera' significa el primer escalón), para poder despolitizar mejor estos enfrentamientos y volverlos susceptibles de un tratamiento estrictamente penal" (Wacquant, 2007, p. 49).

6 En el espacio público, los jóvenes se hacen sentir gracias a la tecnología, música, baile, deporte, graffiti, alcohol y persecución de la autoridad, convirtiéndoles en chivos expiatorios de las iniciativas de mano dura, revestidas con piel de cordero. Allí existe una disputa en y de la esfera pública con su presencia cuestionadora y la acción
} 
$\rightarrow$ La conocida como ventanas rotas, que parte de la lógica causal establecida entre el desorden callejero (espacio público) y la violencia; un desorden que nace del descuido o desinterés de reparar una ventana rota (algo ínfimo), que luego se convierte en una especie de basurero público (algo máximo), lo que, a su vez, convoca a pandilleros, mendigos, alcohólicos y drogadictos, y estos a reclamos del vecindario por seguridad (Kelling y Coles, 2001).

Si no existen estudios que documenten adecuadamente la realidad de esta relación, hay el peligro de que se construya -como de hecho ocurre- un imaginario socialmente estigmatizante y unas propuestas de política que circulan independientemente de los procesos reales. Pero, adicionalmente, se produce un conocimiento a partir de aproximaciones aparentes y banales, nacidas en los medios de comunicación y/o en la urgencia de las políticas públicas.

\section{Ciudad y violencia: ¿causa o relación?}

La violencia no puede entenderse -como tradicionalmente se ha hecho- sólo a partir de las causalidades naturales (por lo tanto biológicas) o morales (vinculadas a la religión o a las tradiciones), como tampoco de su consideración exclusiva de la desviación legal (delito como anomia $)^{7}$. Tampoco es comprensible desde la existencia de una o varias causas, a manera de atributos (llamados factores de riesgo), que la determinan, sino que debe ser concebida como una relación particular del conflicto social (Carrión, 2008) y, por tanto, como una compleja construcción social y politica (Sozzo, 2008) que se cristaliza en un territorio y en un tiempo específico.

Una afirmación de este tipo nos lleva a comprender la violencia como una condición social que tiene múltiples actores, directos e indirectos, que es cambiante en la historia y en el espacio; y que, por tanto, no existe un antes ni un después de un evento, es decir un continuo; sino un objeto (la violencia), construido socialmente en un lugar y un momento específicos (espaciotiempo). No hay una causa para la violencia, ni tampoco múltiples causas para múltiples tipos de violencia; y no las hay, porque ese determinismo unívoco no existe.

La violencia es más que un hecho delictivo por varias razones: porque hay violencias que no están tipificadas legalmente, porque hay una "masa de eventos" (Sozzo, 2008) indiferenciada y porque la criminalidad aparente es un poderoso sentimiento, que no sólo incide en la violencia real -incrementándola- sino que es parte de la misma. Ese temor -a la manera de

estigmatizadora de los medios de comunicación, convirtiéndose en "problema" social que requiere de acciones antidelincuenciales. Son perseguidos y, poco a poco, desplazados del espacio público, utilizando las llamadas (eufemísticamente) estrategias de prevención situacional, que no son tan distintas al ajardinamiento -usado en su momento bajo el pretexto salubrista y de ornato- para desplazar del espacio público a las pueblos y nacionalidades indígenas (Kingman, 2006).

7 Algunas de las limitaciones que tiene la definición legal son las siguientes: primero, que el delito es un acuerdo o pacto social que excluye otras formas de violencia (la violencia de género no fue considerada, durante mucho tiempo, como delito y en algunos lugares aún no lo es); segundo, que cada delito es un hecho que tiene una pena; tercero, que las penas son personales e individualizadas (¡cómo juzgar un linchamiento si es colectivo?); y, cuarto, que el delito se lo registra de manera ex post al hecho producido. 
un imaginario- se convierte en una marcada percepción, que organiza la vida cotidiana, sea como mecanismo social (senderos, solidaridad) o individual (armarse, defensa personal), así como el tiempo y el espacio de la ciudad.

De allí, se puede desprender que la violencia no es una patología social que viene de ciertos atributos (factores de riesgo o causas) ${ }^{8}$ sino una relación social específica del conflicto, que es plural $^{9}$, que tiene historia y que es histórica. En otras palabras, si la violencia no se puede entender a partir de la etiología (Carrión, 2008), la ciudad menos será una de las causas de las violencias; lo cual no debe llevar a desconocer que sí hay una importante relación de la violencia hacia la ciudad y de la ciudad a la violencia.

\section{Ciudad y violencia: ¿̨violencia particular o contenedor?}

Si se parte de la afirmación de que hay una relación histórica entre ciudad y violencia, también habría que interrogarse respecto de si hay una violencia particular que se vive en las ciudades y/o si la ciudad es un escenario contenedor de ella.

La comprensión de las relaciones entre violencia y ciudad requiere ir más allá de aquellas metodologías que las interpretan como si fueran patologías provenientes de ciertos atributos (factores), cuando en realidad se trata de relaciones sociales. Así tenemos:

- Que a la violencia -definida por Álvaro Guzmán (1994, p. 170) - es "necesario concebirla como un producto de una relación social de conflicto que, en consecuencia, vincula por lo menos a un par de oponentes, actores, individuos o colectivos, pasivos o activos en la relación". - Que la ciudad -concebida por uno de los estudiosos clásicos del urbanismo moderno, Louis Wirth - debería entenderse en términos de "un asentamiento relativamente grande, denso y permanente de individuos socialmente heterogéneos" (1988, p. 167).

Si la ciudad -como construcción social- reúne la mayor diversidad posible en un territorio relativamente reducido (densidad), es factible pensar que se trata de una arena de relaciones donde, por un lado, se potencian los conflictos sociales -algunos de los cuales, si no se los procesa adecuadamente, pueden desembocar en hechos de violencia típicamente citadinos

\footnotetext{
8 Por eso, la información proveniente de los indicadores propios de este paradigma (factores de riesgo o hechos) no revelan la realidad profunda (suicidio, género, sicariato) y la pluralidad histórica de las violencias; pero sí construye estigmas; por ejemplo, aquel de que América Latina es el continente más violento del mundo. Si se parte de la definición de violencia usada por la OMS/OPS, uno debe preguntarse por qué son los homicidios (violencia contra otro) y no los suicidios (violencia contra uno) los que califican el grado de violencia - por ejemplo, de un país-, si los dos conceptos tienen igual peso en la definición. Más aún, si en el año 2000 los muertos por guerras fueron $18,6 \%$, los homicidios representaron el 31,3\% y los suicidios el 49,1\% del total de las muertes violentas. Esto es, cerca de la mitad de los fallecimientos violentos provienen de una mortalidad auto afligida. Si esto es así, ¿Por qué -entonces- los homicidios definen los barrios, las ciudades y los países más violentos y no los suicidios? 9 Por eso, así como hay una violencia de género o juvenil que tiene lugar, la primera, en las asimetrías de poder y, la segunda, en el conflicto que plantean las fronteras generacionales en el ámbito de un grupo etáreo; también puede existir -como de hecho así ocurre- una violencia urbana.
} 
(violencia urbana) - y, por otro, que, debido a la densidad y al tamaño de la aglomeración, existe una tendencia hacia la concentración de los eventos violentos (geografía de la violencia).

De allí que la violencia -como relación social particular del conflicto-, que tiene expresión urbana, data desde tiempos inmemoriales, al grado de que se podría afirmar que es consustancial a la ciudad; sin embargo, las violencias que existían en las ciudades del pasado son completamente distintas a las que existen en la actualidad, debido a que la relación violencia-ciudad tiene historia; y a que cada una de ellas son históricas ${ }^{10}$.

Tal afirmación conlleva el reconocimiento de que las violencias viven un proceso de cambio constante, sea por la vía del incremento de su magnitud o de la transformación de sus características ${ }^{11}$. Pero también, la ciudad sufre una transformación por la reducción de las tasas de urbanización (regreso a la ciudad construida); la internacionalización (ciudad global); y la reforma del Estado, que le asigna más poder al Municipio en relación al Ejecutivo nacional (descentralización), aunque menos frente a la ciudad (privatización). En otras palabras, a las dinámicas en los cambios de la violencia y de la ciudad les corresponde la mutación de la relación entre ellas, que desemboca en una concentración de hechos de violencia y en la existencia de una violencia típicamente urbana.

Una primera consideración tiene que ver con el proceso de urbanización: las violencias del campo son distintas a las de la ciudad: mientras en la primera se dirigen más contra las personas, la familia y las tradiciones; en la segunda, los delitos más comunes son contra la propiedad, la de los estadios, las pandillas, las luchas sindicales, el vandalismo y las invasiones, entre otras. Es necesario tomar en cuenta esta distinción, pero también considerar que, si bien en las ciudades hay más delitos que en el campo, eso no quiere decir que las ciudades tengan las tasas de delitos más altas.

Es interesante observar que, mientras las tasas de urbanización de América Latina tienen una disminución generalizada, las tasas de homicidios tienen un comportamiento inverso de crecimiento $^{12}$; lo cual no significa -bajo ningún punto de vista- que la reducción de la urbanización incremente la violencia. De igual manera, los países que tienen mayor nivel de urbanización no son los más violentos: Chile, Argentina o Uruguay, que cuentan con tasas de

\footnotetext{
10 "Podemos establecer que la persecución del delito, a la manera de ejercer el control social sobre la población, es en los dos períodos distinta: mientras en el garcianismo hay más énfasis en lo público, en los delitos que afectan al funcionamiento del Estado teocrático, en el liberalismo hay mayor preocupación por los delitos que atentan contra el individuo y la propiedad" (Goetschel, 2005, p. 69).

11 En estos últimos 25 años, el cambio más importante de las violencias ha sido el paso de la tradicional a la moderna; esto es, de aquellas que se desarrollan por cultura, por estrategias de sobrevivencias o por asimetrías de poder, a las que tienen una predisposición explícita a cometer un hecho delictivo y, por lo tanto, se organizan, internacionalizan y desarrollan tecnológicamente. (Carrión, 2008).

12 Mientras, por un lado, en 1980, la tasa de urbanización fue de 3.2, en la actualidad es del 1.8 por ciento, lo cual quiere decir que casi se redujo a la mitad en estos 25 años (Hábitat); por otro, la tasa de homicidios se duplica en el mismo periodo: "En 1980, el promedio de homicidios por cada 100.000 habitantes era de 12,5 al año. En 2006 fue de 25,1 lo que significa que la criminalidad se ha duplicado en el último cuarto de siglo" (Kliksberg, 2008, p. 5).
} 
urbanización altas, tienen -contrariamente- tasas de violencias bajas, al menos comparativamente con los países que tienen menor nivel de urbanización y mayores tasas de violencias, como son: Ecuador, Guatemala y Bolivia, entre otros.

Si nos adentramos en algunos de los países de la región, se puede observar que las ciudades más grandes no son aquellas que tienen las tasas de violencia más altas. En México, la ciudad de México no tiene más violencia que Guadalajara; en Colombia, Medellín y Cali tienen más inseguridad que Bogotá; en Brasil, Río de Janeiro, a pesar de su tasa alta de violencia, no tiene una tasa superior que la de Recife y San Paulo no tiene más inseguridad que Río de Janeiro; en Chile, las tasas más altas de violencia están en las regiones del norte, que superan a la región central, donde se encuentra Santiago. En otras palabras, no se puede plantear, mecánicamente, que mientras mayor es la urbanización mayor es la violencia.

Sin embargo, sí existe urbanización de la violencia, en el sentido en que se observa un traslado de la violencia del campo a la ciudad, un incremento de las magnitudes y una diferenciación sutil entre las violencias de la ciudad y las del campo, que definen, en su conjunto, el concepto de violencia urbana. Esto es, de una violencia particular, que se desarrolla en la ciudad (como escenario) y en un tipo de urbanización proclive a la generación de una violencia específica, generalmente vinculada a los asuntos de convivencia social.

Es decir que, con la urbanización de la violencia se produce un doble efecto coincidente: que la ciudad es productora de un tipo particular de las mismas: la violencia urbana y también la condición de un escenario contenedor de las violencias; en el sentido de ser práctica social que se desarrolla y expresa en el espacio.

\section{Relaciones mutuas: ciudad y violencia}

Así como no se puede negar que la violencia se ha convertido en un componente primordial para la comprensión de la ciudad, tampoco se puede dejar pasar por alto que la ciudad logra imprimir algunas cualidades explícitas a la comprensión de la violencia. Es imposible negar que la violencia genera un tipo particular de organización espacial-por ejemplo- a través de la proyección de los imaginarios del miedo, que se convierten en un elemento constructor de ciudad $^{13}$, o que la conflictividad de la ciudad sí produce una violencia específica. Eso supone que entre ellas hay una relación dialéctica y no -como ciertas visiones hegemónicas lo piensan, desde la perspectiva de las llamadas multicausalidades- un determinismo unidireccional y unívoco, bajo un orden sucesivo, nacido en los llamados factores de riesgo.

De esta realidad se puede encontrar, al menos desde la perspectiva que nos interesa en el presente trabajo, las relaciones mutuas que vienen desde la violencia hacia la ciudad y desde ésta a las violencias, porque no se puede desconocer que las producciones sociales de la ciudad y de la violencia tienen también consecuencias importantes en el otro componente de la ecuación.

13 "El tema de la inseguridad quizá sea el imaginario más fuerte que se manifiesta en las ciudades de América Latina” (Silva, 2003, p. 84). 


\section{De la ciudad a la violencia}

Si bien la variable urbana no tiene la condición determinista asignada por las corrientes etiológicas de la violencia, no se puede desconocer que la producción social del territorio sí es un elemento importante en el comportamiento de ciertos tipos de violencias. Existe una geografía de la violencia que no es sólo la manifestación de los hechos violentos en el territorio (escenario) sino también un elemento relevante en la producción de los mismos (violencia urbana). Este elemento viene de la división social del espacio y de una lógica particular de urbanismo que puede producir un tipo de violencia particular acorde a la segregación urbana (localización residencial, densidad y de actividades) y a sus implicaciones sociales (foraneidad y temor), que bien vale la pena señalar:

\section{Los usos de suelo}

Sin duda, los usos de suelo (zooning) tienen una importancia significativa en la producción de algunos tipos de violencias; tan es así, que una afirmación tan simple y suficiente como aquella verdad de perogrullo de "se roban bancos donde hay bancos" se convierte en un elemento clave para entender que ciertas violencias tienen una relación directa con la organización espacial. Esto, porque hay una especialización delictiva acorde al uso del suelo. Por ejemplo: el robo de vehículos se produce en las inmediaciones de las zonas bancarias y comerciales, pero -además- en días y horarios laborales. Los delitos callejeros más frecuentes tienen senderos y puntos claramente identificados y se los vincula, por ejemplo, con algunas paradas de la transportación colectiva, con ciertos lugares de la centralidad urbana o con determinados espacios públicos (PEC-FLACSO-Ecuador, 2008). En estos casos, los hechos de violencia no pueden estar disociados de las variables tiempo y espacio.

Esta constatación debe conducir a la formulación de algunas políticas de seguridad que partan de la imprescindible necesidad de no contaminar la planificación física, con los intentos por criminalizarla, así como tampoco de construir el "sueño de un orden". Esto supone acciones de seguridad por usos de suelo (distribución de recursos), así como de una planificación urbana que reduzca las desigualdades (densidades, servicios), construya múltiples centralidades y reconozca órdenes distintos. Todavía más, es necesario recuperar la geografía de la violencia, no para la estigmatización socioterritorial sino para contar con información georeferenciada que permita la toma de decisiones acordes a la realidad.

\section{La segregación residencial}

La localización diferenciada de la sociedad en el territorio crea una violencia simbólica y real que, finalmente, se expresa en las relaciones excluyentes entre los lugares de despliegue de la población de altos recursos económicos y de los de bajos, convertidos en elementos centrales de la desigualdad. Una realidad tan heterogénea e inequitativa como la existente en el espacio urbano (segregación urbana), lleva a incrementar la inseguridad por desigualdad e inequidad, debido a que induce a la violencia: vandalismo, revancha social, percepción de inseguridad, estereotipos, estigmas (que se hacen emblemas) y búsqueda, por fuera del mercado, de lo que otros tienen (invasiones). 
La segregación residencial crea barreras de diferenciación que conducen a la desigualdad y, por tanto -también-a la violencia. Paradójicamente, son las mismas políticas de seguridad las que tienden a acrecentar la segregación: se criminaliza la ciudad de los otros -la de los pobres- la ciudad bárbara y, con ello, se camina hacia el fin de la "otredad"14. La ciudad -esencial y semántica-, ámbito de encuentro con el otro, termina siendo el espacio de la exclusión ${ }^{15}$.

Con la segregación residencial se confirma que, mientras los pobladores de los barrios pobres encuentran seguridad en la búsqueda del sentido de pertenencia, de la identidad comunitaria y de la participación colectiva en lo local -así como el intento perenne de borrar los estigmas que vienen desde afuera-; los habitantes de los barrios ricos lo hacen sobre la base de la defensa de la homogeneidad interna, para lo cual se blindan ${ }^{16}$. Por eso, cuando se habla de temores en la ciudad, es dar por sentado que quienes los experimentan de manera especial son los integrados respecto de los excluidos (Castel, 2004, p. 63).

\section{La foraneidad}

La ciudad comienza a cambiar su estructura bajo dos componentes importantes, que Manuel Castells (1999) reseña de la siguiente manera:

- Se pasa de la segregación urbana clásica (donde la unidad de la ciudad no desaparece ni se diluye, porque las partes se integran al todo, gracias al sentido del espacio público y, dentro de él, a la centralidad urbana), a la fragmentación urbana, produciendo una ruptura de la unidad socio-territorial anterior. Y se da paso a la formación de ciudades convertidas en "constelaciones discontinuas de fragmentos espaciales", a la manera de un mosaico de espacios inconexos desde la perspectiva de las identidades, de las funcionalidades de sus partes y de su gobierno.

- Se pasa de una ciudad donde el espacio público es un elemento fundamental para el encuentro, a una donde la movilidad tiende a representar la mutación "del espacio de los lugares, al de los flujos" (Castells), produciendo, por un lado, lo que Borja y Muxí (2004) define como agorafobia y, por otro lado, a un retorno al nomadismo ${ }^{17}$.

Es decir, se pasa de una urbe que contiene una ciudad plural a una ciudad de fronteras, con límites y barreras infranqueables -donde la exclusión es una forma de estar fuera de sí misma (de la ciudad), y lo hace por medio de las rupturas territoriales, generacionales, étnicas, migratorias y de género, entre otras-. Hay que tener en cuenta que las fronteras son sinónimos

\footnotetext{
14 "En una ciudad segregada socio-económicamente, como Santiago, la percepción de inseguridad en los espacios públicos implica la casi inexistencia de interacción entre habitantes pertenecientes a distintos estratos sociales” (Rodríguez y Winchester, 2004, p. 132).

15 La significativa polarización entre ricos y pobres hace que la "relación de dependencia, o al menos de compasión, que subyacía hasta ahora bajo todas las formas de desigualdad, se despliega ahora en un nuevo ningún lugar de la sociedad mundial” (Beck, 1998, p. 91).

16 Ese blindarse se expresa, según Josep Lahosa, en la "bunkerización”, y según Prats, en una "bunkerización identitaria".

17 "En los años recientes, el único espacio público ganado al rápido desarrollo inmobiliario es aquel destinado a satisfacer las demandas de los vehículos motorizados” (Rodríguez y Winchester, 2004, p. 135).
} 
de separación entre nosotros y ellos, donde el paso de unos está reglado y el de otros, negado; es decir, que no todos pueden traspasar.

La fragmentación lleva al habitante de la ciudad a comportarse como un extranjero o forastero, porque cuando no camina por los senderos habituales hacia los lugares de trabajo o de residencia y se sale de su territorialidad cotidiana (barrio), inmediatamente, se le hace sentir forastero $y$, por tanto, se le exige identificación, como si fuera necesario un pasaporte y una visa para ir de un barrio hacia otro; donde cada uno de ellos se expresan como unidades cerradas y autárquicas.

Existen ciudades donde la fragmentación apuntala a que el flujo prevalezca sobre el encuentro, y la exclusión sobre la inclusión; de allí, que salir de su entorno es una transgresión de fronteras, que es penada, y detenerse en el lugar para encontrarse con el otro es un anacronismo. Ahora nuestras ciudades no son de ciudadanos sino de extranjeros porque, además, la fragmentación conduce a la pérdida de los espacios referenciales para la construcción social y para el sentimiento de pertenencia. De allí que la inseguridad sea percibida en el espacio del otro y la seguridad en el espacio al que uno pertenece; por eso, se lo defiende frente al otro y por eso, en esta ciudad de fronteras, siempre se está afuera, excluido, extrañado: foráneo.

\section{El temor}

La ciudad desigual promueve un temor genérico que expresa simbólicamente el riesgo cotidiano de vivirla, aunque de maneras distintas, según la condición social del poblador; de allí que el miedo se haya erigido más fuerte en el imaginario urbano en América Latina. Lo que existe en la actualidad es una ciudad que produce una población temerosa, especialmente al espacio público, y que, en la búsqueda de la seguridad, desarrolla enclaves cerrados, monofuncionales y especializados, a los que De Mattos (2004) los llama artefactos urbanos de la globalización; mismos que abandonan el espacio público para recluirse en el espacio doméstico que, en muchos casos, es más violento y peligroso.

Pero también los imaginarios del temor que la ciudad produce están vinculados a ciertos lugares. Por un lado, de origen natural, hoy enclavados en la centralidad urbana (como son los cerros y los ríos -inicialmente abandonados por las políticas públicas- entre los que se pueden señalar los casos del Panecillo y Machángara en Quito; el Cerro y Miguelete en Montevideo; Monserrat y Bogotá, en Bogotá; o San Cristóbal y Rímac en Lima); y por otro, de producción antrópica, entre los que están los lugares emblemáticos de La Marín en Quito; el Cartucho en Bogotá; Las Malvinas, en Lima; la Estación Central en Santiago; o Tepito en México, entre otros. Uno de los elementos llamativos de estos casos estriba en el hecho de que, independientemente, de que las políticas urbanas hayan llevado importantes acciones de rehabilitación, existe una inercia social que le da permanencia al sentimiento de inseguridad asociada a estos lugares (Carrión, 2008). 


\section{De la violencia a la ciudad}

Si la ciudad no es determinante de la violencia en general y en abstracto, parece conveniente hacer un ejercicio metodológico inverso, para pensar el impacto que la violencia produce en la urbe. Existe la necesidad de plantear una entrada metodológica, que parta del conocimiento de los efectos de las violencias sobre la ciudad, porque el efecto en ella es inconmensurable, en tanto la violencia está menoscabando la esencia de la urbe.

No se puede desconocer que el incremento de la inseguridad, y las pérdidas de vidas humanas y de bienes materiales conducen a que la violencia sea uno de los problemas que más deteriora la calidad de vida urbana y erosiona la condición pública de la ciudad. La merma de las condiciones de vida es, a su vez, parte del proceso (¿causación circular?) de la violencia urbana, con lo cual cada una de las reacciones de defensa de la población terminan siendo un nuevo comportamiento social, que lleva a más violencia: individualismo, angustia, inseguridad, marginación, desamparo, aislamiento, desconfianza, agresividad, etc. En esta perspectiva, se pueden encontrar -al menoscuatro importantes impactos explícitos de la violencia en la ciudad: la ciudadanía, el tiempo, el espacio y la unidad urbana.

\section{La ciudadanía}

Si partimos de la consideración de que la ciudadanía nace históricamente en la ciudad (porque era la unidad política existente), debido a la adscripción o pertenencia de la población a la comunidad -que le otorga derechos y deberes-, podremos convenir en que la violencia restringe el origen y la fuente de la cualidad de la ciudadanía.

Al ser la ciudad el espacio principal para la construcción social, para la constitución de la ciudadanía, para la formación de identidades colectivas y para potenciar las capacidades de socialización, convendremos, además, en que las violencias generan sentimientos contrarios a los anotados. Pero tampoco se debe dejar pasar por alto los efectos indirectos que la violencia y su combate generan en la población; se observa una erosión de la ciudadanía, por cuanto los habitantes, primeras víctimas del fenómeno, empiezan a asumir mecanismos que llevan a modificar su conducta cotidiana: cambios en los horarios habituales; transformación de los senderos y espacios transitados cotidianamente; restricción de las relaciones sociales, porque todo desconocido es sospechoso (fin de la alteridad); reducción de la vulnerabilidad personal adquiriendo armas, perros, alarmas -que ya son parte del paisaje urbano-; o aprendiendo defensa personal ${ }^{18}$.

\section{El tiempo}

Existe una cronología de la violencia, nacida de la relación, indisoluble y estrecha, entre tiempo y violencia, que se expresa a través de dos modalidades: por un lado, que ciertos delitos tienen

\footnotetext{
18 A ello debe sumarse que la crisis económica y las políticas de ajuste implantadas han contribuido a reducir los mecanismos de representación, a restringir los espacios de solución de los conflictos, a mercantilizar las relaciones sociales, a reducir las manifestaciones culturales, propias de la condición de ciudadanía.
} 
una preeminencia en ciertas horas, como por ejemplo, el homicidio es nocturno y vinculado a los días festivos; el suicidio juvenil en las épocas de culminación de estudios; o la accidentalidad pirotécnica al final de año y principio del otro. Una cronología de este tipo produce comportamientos humanos restrictivos y políticas urbanas focalizadas, que tienden a acrecentar las actitudes individuales de la población que, en muchos casos, se convierten en elementos inductores a hechos de violencia o inhibidores de actividades sociales y económicas.

Y, por otro lado, que se produce el efecto de la reducción del tiempo de la urbe, con lo cual las ciudades de la noche tienden a desaparecer al ser prohibitivo salir del espacio privado al público pasadas ciertas horas. Ciertos lugares de la urbe tienen una vida útil por 12 horas o un poco más y el promedio de la misma está a la baja en la mayoría de las ciudades.

\section{El espacio}

La ciudad en construcción va perdiendo espacios públicos y cívicos, se generaliza la urbanización privada-amurallada que segrega aún más; hay una reducción del espacio de la ciudad y, en particular, del espacio público, porque se encuentra al acecho; tan es así, que la agorafobia también es el temor al espacio público que le tienen los sectores más acomodados, además del proceso de privatización que se vive. Las ciudades se hacen cada vez más privadas y domésticas, prueba de ello es el significativo crecimiento que ha tenido la cultura a domicilio: cine en casa, comida en casa y trabajo en casa. Hoy existen ciertas zonas de la ciudad a las cuales ni la policía puede entrar, y cuando el control policial hace su presencia, estos lugares se vacían de ciertos segmentos de la sociedad.

\section{La estructura urbana}

La violencia objetiva (los hechos) y la subjetiva (percepción) se despliegan en el territorio de una ciudad de manera desigual produciendo impactos diferenciados. Uno de ellos, el sentimiento generalizado de inseguridad, hace que las políticas de seguridad públicas, privadas o comunitarias produzcan cambios urbanos en su estructura. Quizás el más notable de estos cambios tenga que ver con el fortalecimiento de la segregación urbana bajo la forma fragmentada. Las urbanizaciones cerradas, los centros comerciales, los clubes sociales y deportivos, la verticalización y las centralidades urbanas, entre otros, tienen mucho que ver con la violencia y el temor que se ha generalizado. Así, "el miedo pareciera haberse constituido en fuerza y motor de la nueva ciudad contemporánea”, según nos lo dice Guerrero (2006, p. 107).

En definitiva, las violencias objetiva y subjetiva producen un impacto inconmensurable en la ciudad, porque la atacan en su esencia: la condición de ciudadanía, relegando su posibilidad de "civitas" o "polis" y reduciendo al tiempo y al espacio como dos de los elementos que redefinen la cualidad urbana; y generando una estructura urbana que se hace más inequitativa.

\section{Espacio público/espacio privado}

En América Latina, el espacio público se encuentra reducido por el peso del mercado que privatiza todo, por la ciudad difusa que le hace perder referentes y por la segmentación que lleva 
al extremo de que es difícil que unos con otros se encuentren en el mismo tiempo y lugar (la otredad). Entonces, la agorafobia se expresa con mayor claridad en el elemento simbólico por excelencia: la plaza, pero también en las calles, parques, veredas. En este contexto, plantearse prevención situacional en el espacio público es, por decir lo menos, un contrasentido ${ }^{19}$, porque si "el espacio público es la ciudad", no hay que maquillar el espacio público actualmente existente sino plantearse el diseńo de un nuevo urbanismo constructor y productor de ciudad, es decir, de espacio público.

Esta condición actual del espacio público proviene al menos de las siguientes tres consideraciones:

a) El paso del "espacio de los lugares al espacio de los flujos" (Castells, 1999), que ha hecho, no del encuentro sino del nomadismo de las personas, de los servicios y de la información su razón de ser.

b) El espacio y el tiempo, socialmente definidos en la globalización, han generado, según palabras de Beck (1998, p. 90), que la alteridad sea difícil de constituirse porque "lo nuevo de la era global es que se ha perdido el nexo entre pobreza y riqueza, y esto es, según Bauman, a causa de la globalización que divide la población mundial en ricos globalizados, que dominan el espacio y no el tiempo, y pobres localizados, que están pegados al espacio y tienen que matar su tiempo, con el que no tienen nada que hacer".

c) El espacio público, otrora un lugar de encuentro de los distintos, pierde el sentido de inclusión y se convierte en un no lugar ${ }^{20}$, en tanto queda circunscrito únicamente para los pobres, mientras los ricos construyen sus escenarios privados bajo la lógica de los públicos (el barrio frente a la barriada, el mall frente a la feria, el parque frente al jardín); y lo más grave, el espacio público es sometido a un acoso permanente (agorafobia), al extremo en que la plaza-símbolo principal del encuentro social y urbano- es, hoy, una especie en vías de extinción ${ }^{21}$.

En este contexto, el espacio público debe convertirse en un elemento básico en la constitución de una nueva forma de inclusión social y territorial. Porque sin espacios públicos de calidad no hay convivencia posible ni estructura urbana satisfactoria y, por lo tanto, tampoco

\footnotetext{
19 Hasta ahora, la prevención situacional ha estado marcada por tres tipos de acciones en el espacio público: primero, por cámaras de video, policía comunitaria, respuesta temprana; segundo, por la expulsión de ciertos segmentos de población (jóvenes, indigentes, etc.) bajo el criterio de privatización y del estricto derecho de admisión; y, tercero, la dotación de servicios y equipamientos, en ciertos espacios previamente focalizados como peligrosos (la ciudad de los otros, así los clasifica y estigmatiza).

20 "Si un lugar puede definirse como lugar de identidad, relacional e histórico, un espacio que no puede definirse ni como espacio de identidad ni como relacional ni como histórico, definirá un no lugar” (Augé, 1998, p. 83).

21 “... la de construir una plaza pública en torno a una ciudad cerrada al campo. Porque, en efecto, la definición más acertada de lo que es la urbe y la polis se parece mucho a lo que, cómicamente, se da del cañón: toma usted un agujero, lo rodea usted de alambre muy apretado, y eso es un cañón. Pues lo mismo, la urbe o polis comienza por ser un hueco: el foro, el ágora; y todo lo demás es pretexto para asegurar ese hueco, para delimitar su dintorno. La polis no es primordialmente un conjunto de casas habitables, sino un lugar de ayuntamiento civil, un espacio acotado para funciones públicas” (Ortega y Gasset, 2004, p. 185).
} 
seguridad ciudadana. Por eso, el ordenamiento y construcción del espacio público no es una tarea en absoluto policial (represión), ni tampoco es un proceso de apropiación excluyente del control social (disciplinador). El espacio público es el espacio de la disputa por la libertad, la integración, la visibilidad, la representación y no del control social en cualquiera de sus formas (Carrión, 2007).

Se puede ejemplificar esto con tres casos interesantes que transitan de lo privado a lo público, sin estar exentos de conflictos: dos, provenientes del ámbito de dos tipos de violencias (género y pandillas); y otro, que viene de las políticas de seguridad implantadas (seguridad privada). Estos ejemplos tienen la virtud de mostrar que esta dicotomía es más que ello.

\section{Violencia de género}

La violencia de género es reconocida como una violencia específica (delito) desde no hace mucho tiempo -al menos en América Latina-, y lo hace al momento en que se produce la transición del ámbito doméstico y privado en el que se expresaba -por tanto, supuestamente exento de visibilidad-, hacia el espacio público. Este reconocimiento de la violencia de género se consigue cuando se la asume bajo la óptica de la seguridad ciudadana, lo cual produjo dos cambios importantes: por un lado, se registró como un ámbito de los derechos de la población, en particular de los relacionados con los procesos de ciudadanización de las mujeres; $y$, por otro, se reconoció como una forma de superar el mundo privado-doméstico, para visibilizarse como parte del ámbito público, eliminando la dicotomía público-privado. En otras palabras, uno y otro fueron directamente vinculados al tema de la democracia (polis), en términos del respeto a la diversidad, de la satisfacción de derechos y de la formación de una comunidad de sentido urbana.

En el espacio privado, se ejerce la violencia hacia la mujer, pero, al convertirse la seguridad en un derecho, se produce el tránsito hacia el ámbito público; sin embargo, hay que afirmar que la violencia no se define por el lugar donde ocurre sino por las asimetrías de poder que existen entre los sexos, ejercidas de manera ubicua en el territorio. Empero, justo es reconocer que cambiar los patrones inequitativos de género ha sido más factible en las ciudades que en el campo, porque, mientras en el campo están asentadas las tradiciones culturales que le asignan a la mujer roles que son distintos y específicos, en la ciudad se hace pública, se visibiliza y se le reconocen sus derechos.

\section{La violencia de las pandillas}

En el caso de la violencia originada alrededor de las pandillas, hay que comprender que ésta se convierte en el sustituto institucional que construye el joven, para sentir la posibilidad de ser parte de la vida cotidiana. Es un mecanismo, frente a la escasa libertad que tiene el joven en el espacio privado-doméstico, que le obliga a salir a disputar, en el espacio público, su sentido de existencia; sentido que le es esquivo porque su apropiación social y simbólica tiene una condición de ocupación excluyente entre las pandillas y la autoridad (policía, municipio). En esa disputa por el espacio público, una vez que la policía se hace presente, se pasa de un conflicto difuso en términos de la existencia de una pluralidad de actores (otras pandillas, 
comunidad, policía, municipios) a un conflicto polarizado de actores, donde las políticas de seguridad tienden a delinearse a partir del concepto de la amenaza interna y a definir las pandillas como neo enemigos.

Los jóvenes emancipados de sus familias, propias del entorno privado-doméstico, encuentran en la pandilla -propia del espacio público-colectivo- un escenario de expresión simbólica e integración social22. Ahí, ejercen pertenencia y autoridad, y se sienten parte de una élite, reconocida por los medios de comunicación y por las políticas públicas. En esa perspectiva, el espacio público es un elemento constitutivo de la seguridad y de la identidad del grupo; ahí construyen su comunidad de sentido callejero, barrial, urbano e incluso -en la actualidad y en ciertos casos- virtual. El anclaje territorial inicial que caracterizaba a la pandilla (de base local-barrial) es superado por la existencia de la pandilla global-virtual. El fenómeno migratorio, las nuevas tecnologías de la comunicación y la apertura de los mercados internacionales dan lugar a nuevas estrategias de los grupos de emigrantes juveniles, logrando establecer lazos entre los lugares de origen y destino, como territorios, primero, diferenciados y, luego, indiferenciados, gracias a la integración virtual (Internet); lo cual significa que la pandilla -que tiene como origen el control de su espacio inmediato- termina transformando su espacio barrial en uno virtual.

\section{La seguridad privada}

El caso de la seguridad privada es interesante, porque desde lo público-estatal se planteó, como parte de la reforma del Estado, la desregularización, que introdujo las condiciones mínimas para la privatización de la seguridad. Además, el incremento de la violencia legitimó su presencia, por la ineficiencia estatal para controlarla. De esta manera, la seguridad privada tiene un tránsito: de lo público-estatal a lo privado-empresarial y de ésta al espacio público.

Desde mediados de la década de los ochenta, se percibe un crecimiento expansivo del mercado de bienes y servicios privados de la seguridad ciudadana. Según Frigo (2003, s/n): “en Latinoamérica, la seguridad privada es un sector económico en rápida expansión (...). En los últimos 15 ańos, como actor de la vida económica, la seguridad privada ha ganado un lugar de relevancia, tanto en el mundo como en nuestra región (...). El mercado mundial de la seguridad privada tuvo el ańo pasado un valor de 85.000 millones de dólares, con una tasa de crecimiento anual promedio del 7\% al 8\% (...). En Latinoamérica, se estima un crecimiento del 11\%."

Esta condición económica posiciona a un nuevo actor político (la seguridad privada) en el escenario de la seguridad ciudadana, y lo hace bajo un nuevo precepto: la rentabilidad de los capitales invertidos. Pero, además, lo convierte también en un actor singular en el control del orden público; es decir, en la seguridad pública. Hoy, en América Latina, la guardianía

\footnotetext{
22 "La pandilla es una organización de tipo fraternal que brinda a los muchachos autonomías con respecto a la autoridad adulta. Estos jóvenes... al carecer de libertad en el hogar, construyen su propia privacidad en los espacios públicos urbanos, donde se siente protegidos contra la autoridad" (Goubaud, 2008, p. 36).
} 
privada (más de 4 millones) tiene más del doble de efectivos de los que tienen las policías públicas (más de 2 millones).

Una situación como la descrita introduce dos elementos que nos interesa resaltar: el cambio del derecho universal a la seguridad ciudadana a la conversión en un objeto de transacción económica -según la oferta y la demanda-, proceso en el cual se crea un mercado altamente segmentado y, en cierto sentido, excluyente. Y, lo paradójico: el propio Estado es uno de los principales demandantes del servicio convertido en mercancía. Con todo ello, lo que tenemos es un servicio público convertido en un servicio privado que actúa en el ámbito público y lo hace de manera excluyente: el que tiene dinero tiene seguridad y el que carece de recursos no accede al "servicio". ¿ Seguridad privada o privación de la seguridad?

\section{Conclusiones}

Hoy, luego del fin de la guerra fría, el debate central sobre la violencia y la seguridad ciudadana está centrado en la posibilidad y necesidad de romper con el unilateralismo de las visiones dominantes y hegemónicas, tan en boga.

La ciudad dejó, hace mucho, de ser concebida como un problema, porque es el lugar en donde se construyó la ciudadanía, es el espacio en donde se han producido las mayores innovaciones, es el ámbito productivo por excelencia, es la instancia en donde se pueden satisfacer de mejor manera los servicios elementales, es el escenario en donde el empleo crece y la pobreza se reduce, así como también, donde la mujer se hace pública, el joven se expresa, la política se construye. Una consideración de este tipo es fundamental para no caer en el prejuicio de la causalidad y para entender que con buenas políticas urbanas se puede hacer mucho en la perspectiva de 'des-seguritizar' las relaciones interpersonales y satisfacer las libertades públicas e individuales.

Si partimos de la evidencia de que la crisis del espacio público es la expresión más significativa de la crisis urbana (Carrión, 2007), se puede concluir que las políticas urbanas y la planificación urbana pueden aportar mucho al redireccionamiento del urbanismo. En otras palabras, el desarrollo y la construcción de nuevos espacios públicos -como espacios significantes y simbióticos- sólo serán posibles con un nuevo urbanismo y con nuevas políticas públicas.

Hay una relación dialéctica entre ciudad y violencia, que permite estructurar dos perspectivas analíticas importantes: la una, con una dinámica que proviene de los cambios en los elementos de la ecuación que -a su vez- llevan a mutar la relación (esto es, que la violencia, la ciudad y sus relaciones son históricas); y, la otra, que es evidente que hay algunas violencias que son propias de la ciudad (violencia urbana) y, además, que la ciudad es un espacio donde ocurren múltiples actos violentos (escenario, contenedor).

Esto significa que es necesario intervenir con políticas urbanas y con políticas de seguridad ciudadana para obtener resultados positivos. Allí están, entre varios ejemplos, la violencia que introduce el transporte, sea por la vía de los accidentes o del uso del servicio bajo formas violentas; las invasiones que, aunque han bajado en la región, siguen existiendo como 
formas de transgresión violenta a la propiedad inmueble; la violencia en los estadios también es típicamente urbana, no sólo por el emplazamiento urbano de los escenarios sino también porque hay una vinculación entre las barras bravas y las pandillas; las pandillas generan una violencia típicamente urbana, que se ancla territorialmente alrededor del barrio, incluso, de su transnacionalización ${ }^{23}$.

Los municipios hacen muy poco en el ámbito de la seguridad y, ante la demanda creciente de la población, lo que han hecho es criminalizar las políticas urbanas tradicionales; es decir, hacer lo que venían haciendo, pero esta vez maquillando con el cambio de nombre. Por eso, si se parte de la afirmación de que "lo que está en el presupuesto es lo que se hace", convendremos en que la participación municipal en el ámbito de la seguridad es más un deseo o un proyecto que una realidad. Esta afirmación no niega el hecho de que existan algunos municipios en la región que tengan políticas importantes e interesantes, sobre todo en Colombia y Brasil.

La definición de las políticas públicas en el ámbito de la seguridad ciudadana es el resultado de acuerdos políticos amplios: de consensos, de hegemonías y de correlación de fuerzas en distintos escenarios (parlamentos, policías, ministerios). La llamada "voluntad política" no es otra cosa que el resultado de ello: toda política pública es política, es ejercicio de poder en determinadas coyunturas y espacios. Por eso, la técnica y los tecnócratas son actores adicionales, como son la cooperación internacional, los medios de comunicación o las universidades, y cada uno de ellos con su peso político.

Vientos nuevos se empiezan a percibir. Si las elecciones nacionales anteriores al año 2007 estuvieron centradas en la oferta de las distintas versiones de la "mano dura" (policía, pena de muerte, la tercera es la vencida), hoy da la impresión de que ese ciclo podría estar entrando en una fase terminal. Álvaro Colom, en Guatemala; Fernando Lugo, en Paraguay; y Leonel Fernández, en República Dominicana, pueden abrir nuevos cauces y pueden producir un desplazamiento de los ejes tradicionales de los llamados "casos exitosos".

\section{Referencias bibliográficas}

Arboleda, M. (1999). Equidad de género: el campo municipal como espacio de derechos y políticas. Mimeo.

Augé, M. (1998). Los no lugares. Espacios del anonimato. Barcelona: Gedisa.

Beck, U. (1998). ¿Qué es la globalización? Barcelona: Paidós.

Bohigas, O. (2003). En defensa de la urbanidad. En J. Borja \& Z. Muxí (Eds.), Espacio público: ciudad y ciudadanía. Barcelona: Electra.

Borja, J. \& Castells, M. (1998). Local y global. Madrid: Ed. Taurus, Madrid.

Borja, J. \& Muxí, Z. (2003). El espacio público: ciudad y ciudadanía. Barcelona: Electra.

Carrión, F. (1994). De la violencia urbana a la convivencia ciudadana. Pretextos, 94, 6, 27 48.

\footnotetext{
23 Es interesante resaltar el caso de la pandilla llamada Latin Kings, que nace gracias a los fenómenos de migración internacional y que opera en las ciudades, articulada en red. Por ejemplo, en Guayaquil, Quito, New York y Murcia. El caso de las Maras en Centro América y de los Pachuchos en México también son ejemplos interesantes.
} 
Carrión, F. (2005). Pobres las ciudades de pobres. La Paz: Ed. OXFAM.

Carrión, F. (2007). El espacio público, punto de partida para la alteridad. En O. Segovia (Ed.), Espacios públicos y construcción social. Hacia un ejercicio de ciudadanía. Santiago de Chile: SUR.

Carrión, F. (2008). La seguridad en su laberinto. Quito: FLACSO Ecuador-IMDQ.

Castel, R. (2004). La inseguridad social. ¿Qué es estar protegido? Buenos Aires: Manantial.

Castells, M. (1999). La era de la información. Barcelona: Siglo XXI.

Crawfort, A. (1998). Crime prevention and community safety. Politics, policies and practices. London: Lomgman.

De Mattos, C. (2004). Santiago de Chile: metamorfosis bajo un nuevo impulso de modernización capitalista. En C. De Mattos, M.E. Ducci, A. Rodríguez \& G. Yáñez Warner (Eds.), Santiago en la globalización: ¿una nueva ciudad? Santiago de Chile: SUR-EURE.

Facultad Latinoamericana de Ciencias Sociales (FLACSO), Ecuador (2008). Boletín Ciudad Segura No 17, Georreferenciación de la inseguridad. Quito: FLACSO -IMDQ.

Frigo, E. (2003). Hacia un modelo latinoamericano de seguridad privada: los nuevos desafios en la región. Conferencia del Primer Congreso Latinoamericano de Seguridad, Bogotá, Colombia.

Goetschel, A. M. (2005). La cárcel en el Ecuador, vida cotidiana, relaciones de poder y politicas públicas. Mimeo, Flacso-Ecuador.

Goubaud, E. (2008). Maras y pandillas en Centroamérica. URVIO, 4, 35-46.

Guerrero, R. M. (2006). Nosotros y los otros: la segregación urbana y significados de la inseguridad en Santiago de Chile. En M. A. Aguilar, D. Hiernaux \& A. Lindón (Eds.), Lugares e imaginarios en la metrópolis. Barcelona: Anthropos - UAM.

Guzmán, A. (1994). Observaciones sobre violencia urbana y seguridad ciudadana. En F. Carrión (Ed.), Ciudad y violencias en América Latina. Cali: PGU-Alcaldía Cali.

Jordán, R. \& Simiodi, D. (2002). Las nuevas funciones urbanas: gestión para la ciudad sostenible. Santiago de Chile: CEPAL.

Kelling, G. \& Coles, C. (2001). No más ventanas rotas. México: Instituto Cultural Ludwig Von Mises.

Kingman, E. (2006). La ciudad y los otros, Quito 1860-1940: higienismo, ornato y policía. Quito: FLACSO - Ecuador.

Kliksberg, B. (2008). ¿Cómo enfrentar la inseguridad en América Latina? Nueva Sociedad, 215, pp. 4-16.

Londoño, J. L.; Gaviria, A. \& Guerrero, R. (Eds.) (2000). Asalto al desarrollo: violencia y crimen en las Américas. Washington: Banco Interamericano de Desarrollo - BID.

MacDonald, J. \& Simiodi, D. (1999). Consensos urbanos. Aportes del Plan de Acción Regional de América Latina y el Caribe sobre asentamientos humanos. Santiago de Chile: CEPAL.

Organización Internacional del Trabajo (OIT) (2003). Panorama laboral. Lima: OIT.

Organización Panamericana de la Salud (OPS) \& Organización Mundial de la Salud (OMS) (2002). Informe mundial sobre la violencia y la salud. Washington D.C: OPS.

Ortega y Gasset, J. (2004). La rebelión de las masas. Barcelona: Cayfosa.

Rodríguez, A. \& Winchester, L. (2004). Santiago de Chile: una ciudad fragmentada. En C. De Mattos, M.E. Ducci, A. Rodríguez \& G. Yánez Warner (Eds.), Santiago en la globalización: ¿una nueva ciudad? Santiago de Chile: SUR-EURE.

Silva, A. (2003). Bogota imaginada. Bogotá: Taurus. 
Sosso, M. (2008). Inseguridad, prevención y policía. Quito: FLACSO-Ecuador-IMDQ. Wacquant, L. (2007). Los condenados de la ciudad. Gueto, periferias y Estado. Buenos Aires: Siglo XXI.

Wirth, L. (1988). El urbanismo como modo de vida. En M. Bassols, R. Donoso, A. Massolo \& A. Méndez (Eds.), Antología de sociología urbana (pp. 162-182). México: Universidad Nacional Autónoma de México (UNAM). 